\title{
Avaliação de Cinco Híbridos de Milho (Zea mays, L.) em Diferentes Estádios de Maturação. 4. Digestibilidade da Matéria Seca, Matéria Orgânica e Fibra em Detergente Neutro da Porção Vegetativa e Planta Inteira ${ }^{1,2}$
}

\section{Lúcia Maria Zeoula ${ }^{3}$, Juliano Ricardo Fontanini Beleze ${ }^{4}$, Ulysses Cecato ${ }^{3}$, Clóves Cabreira Jobim ${ }^{3}$, Luiz Juliano Valério Geron ${ }^{5}$, Odimári Pricila Pires do Prado ${ }^{5}$, Alencariano José da Silva Falcão ${ }^{6}$}

\begin{abstract}
RESUMO - O objetivo do presente estudo foi avaliar cinco híbridos de milho (Zea mays L.), quanto à digestibilidade in vitro da matéria seca, matéria orgânica da planta inteira e do colmo, em diferentes estádios de maturação. Os tratamentos utilizados foram em parcelas de 7 x $8 \mathrm{~m}$ em um delineamento de blocos ao acaso, com quatro repetições. A colheita das amostras dos híbridos de milho Pioneer (P32R21, P30R07, P3041, P30F33 e P30F80) foi adotada estimando-se os cinco estádios de maturação da planta propostos (30, 34, 38, 42 e 46\% de matéria seca). Na planta inteira, foram determinadas a digestibilidade in vitro da matéria orgânica (DIVMO) e a digestibilidade in vitro da matéria seca (DIVMS). Na fração colmo + bainha, determinou-se a digestibilidade in vitro da FDN (DIVFDN) e DIVMS. A DIVMS e DIVFDN do colmo + bainha praticamente não variaram após a formação do grão (25\% de MS na planta), com exceções para os híbridos superprecoce P32R21 (aumentou) e o semiprecoce P30F80 (diminuiu), apresentando os melhores valores para faixa de 25 a 39\% de MS. Já a DIVMS e DIVMO da planta inteira praticamente não variaram após a formação do grão, com exceção do precoce P30F33, que aumentou em quinze unidades percentuais. Quando os teores de MS se elevaram de 30 para $35 \%$, os melhores coeficientes de digestibilidade foram observados para faixa de 30 a $38 \%$ de MS.
\end{abstract}

Palavras-chave: digestibilidade, estádios de maturação, milho

\section{Evaluation of Five Corn Hybrids (Zea mays, L.) at Different Maturity Stages. 4. Dry Matter Digestibility, Organic Matter and Neutral Detergent Fiber (FDN) of the Vegetative Portion and Whole Plant}

\begin{abstract}
The objective of this study was evaluate five corn (Zea mays L.) hybrids, while the dry matter "in vitro" digestibility, organic matter of whole plant and of the stem, at different maturity stages. The treatments were used in plots of $7 \mathrm{x} 8 \mathrm{~m}$ in a randomized block design, with four replicates. The samples collected, of corn hybrid Pioneer (P32R21, P30R07, P3041, P30F33 and P30F80), were adopted trying to estimate phases of maturity of the plant: 30, 34, 38, 42 and $46 \%$ of dry matter (DM)). In the whole plant were determinated the organic matterin vitro digestibility (IVOMD) and the dry matterin vitro digestibility (IVDMD). From the stem + sheath fraction, the neuter insoluble fiber in vitro digestibility (IVNDFD) and IVDMD was determinated. The IVDMD and IVNDFD the stem + sheath practicable did not variable after a grain formation (25\% the DM plant), with exceptions at the hybrids P32R21 (increased) and P30F80 (decreased) presented at the greatest variations at 25 a 39\% DM. AIVDMD and IVOMD the whole plant, practicable did not change after a grain formation, except for the P30F33 hybrid at fifteen percentage units. When the DM levels increased from 30 to $35 \%$, the best coefficients of digestibility were observed from 30 to $38 \%$ DM level.
\end{abstract}

Key Words: corn, digestibility, stages of maturation

\section{Introdução}

A utilização da silagem de milho na alimentação dos ruminantes, principalmente para vacas leiteiras, expandiu rapidamente, devido ao seu alto valor nutritivo e, portanto, alto conteúdo energético, por fácil de ser produzida e bem consumida pelos animais. Nos países europeus, onde essa cultura é possível, a silagem de milho é à base da alimentação dos bovinos que apresentam produções elevadas e altas exigências nutricionais no inverno (vacas leiteiras e novilhos inteiros em regime de engorda) (Demarquilly, 1994).

Desde de 1978, após extensa revisão sobre os fatores que influem na qualidade da silagem, Hunter

\footnotetext{
1 Projeto financiado pela PIONEER SEMENTES, com parceria da FUNDAÇÃO ABC.

2 Parte da Dissertação de Mestrado apresentada pelo segundo autor.

3 Professores do PPZ/ DZO/UEM. Av. Colombo, 5790 - 87020-900, Maringá - PR. Bolsista do CNPq. E.mail: Imzeoula@uem.br

${ }_{4}$ Médico - Veterinário, mestre em Produção Animal - PPZ/UEM. E.mail: jbeleze@hotmail.com

5 Estudante de graduação em Zootecnia - DZO/ UEM - Bolsista de Iniciação Científica/ CNPq.

6 Estudante de doutorado em Melhoramento Genético - PPZ/UEM.
} 
questionou sobre a importância da participação de grãos como o principal responsável pela qualidade e produtividade da silagem de milho. Esse autor apontou uma variação genotípica para a qualidade da planta dentro dos materiais utilizados para produção de grãos, que refletiriam no consumo de MS e na digestibilidade da forragem, independente da relação grão/planta. Concluiu que, para melhorar a qualidade da silagem, era necessário que a parte não constituída de grãos fosse também de boa qualidade.

Allen (1990), analisando as silagens de 33 híbridos de milho por dois anos consecutivos, observou que, a amplitude dos coeficientes de digestibilidades in vitro da matéria seca (74 a 80\%) e da fibra (41 a $46 \%$ ) das silagens, variaram muito pouco, quando comparadas com as amplitudes nos teores da fibra em detergente ácido ( 38 a 53\%) e da percentagem de grãos na matéria seca (22 a 53\%). O autor conclui que, apesar da percentagem de grãos na matéria seca (MS) variar amplamente, a digestibilidade da MS se manteve estável, indicando que além da percentagem de grãos na produção de MS, outros componentes da planta também desempenhavam papel preponderante sobre a qualidade da forragem ensilada.

As diferenças observadas na digestibilidade entre as variedades de milho podem estar relacionadas ao teor de grão ou de espiga para um certo estádio de crescimento da planta e à composição morfológica, muito diferente entre os híbridos. Porém, essa variação na digestibilidade resulta, principalmente, das diferenças na digestibilidade da parede celular (planta sem o grão). Isto é bem demonstrado pela ausência total de relação entre a digestibilidade da matéria orgânica (DMO) da planta de milho e seu teor de amido e da estreita relação entre a DMO e o seu teor em parede celular não digestível (FDN indigestível) $\left(\mathrm{R}^{2}=0,975\right)$, como observado por ANDRIEU et al. (1993).

Demarquilly (1994) e Mayombo et al. (1997) observaram que a digestibilidade da planta inteira do milho variou quase nada entre a floração e o estádio de colheita, quando o teor de grão passa de zero a 40$50 \%$. Demarquilly (1994) observou valor médio para a digestibilidade da matéria orgânica (MO) da silagem de milho de $71,5 \pm 2,2 \%$ e Mayombo et al. (1997) encontraram valores médios sobre a digestibilidade da MS e da MO da planta inteira, em média, de 76,8 e $77,5 \%$, respectivamente.

Segundo Barrière et al. (1997), as variações no valor alimentar de cultivares de milho estão relacionadas com a digestibilidade do colmo da planta, com a variação no conteúdo de grão, com a variação na ingestão e com as interações digestivas entre a forragem e o concentrado fornecido na dieta. A digestibilidade da parede celular depende, em parte, das suas características intrínsecas, principalmente do teor de lignina, as quais definem a sua susceptibilidade à degradação microbiana.

Segundo Almeida Filho (1996), a digestibilidade da parede celular é uma característica que apresenta variação genética entre híbridos e sua herdabilidade é alta. A melhoria das características de qualidade e a seleção para maior digestibilidade da parede celular é possível, sem afetar a produção de grãos ou a produção da planta.

Dados de 308 híbridos, registrados na França e na Bélgica, foram analisados no INRA Lusignan (1998) e não foi observada relação linear entre o valor energético e o seu teor em grão. A variação no teor de amido de 11 a $40 \%$ não influenciou o valor energético, visto que, a DMO variou somente em 8 pontos percentuais na digestibilidade $(65,2$ a $73,5 \%)$. A não relação entre o teor energético e o teor em grãos pode ser explicada pelo fato de que o milho pode ter um bom valor energético e ser relativamente pobre em grãos, mas, ter o colmo de excelente qualidade (alta digestibilidade). De modo que, as variedades de milho com colmos de melhor digestibilidade e teor de grão normal permitirão maior produção de leite com economia de 1,0 a 1,5 kg de concentrado/animal/dia.

O objetivo deste trabalho foi avaliar híbridos de milho para silagem, quanto digestibilidade in vitro da matéria seca e da fibra em detergente neutro da fração colmo + bainha e a digestibilidade in vitro da matéria seca e da matéria orgânica da planta inteira, em diferentes estádios de maturação.

\section{Material e Métodos}

O plantio dos híbridos de milho Pioneer foi realizado na fazenda experimental "Capão Alto", pertencente à Fundação ABC, formada pelas Cooperativas Arapoti Ltda, Agropecuária Batavo Ltda e Sociedade Cooperativa Castrolanda, localizada no município de Castro, região sul do estado do Paraná.

As análises químicas e a digestibilidade in vitro foram realizadas no Laboratório de Alimentação e Nutrição do Departamento de Zootecnia da Universidade Estadual de Maringá.

O plantio dos híbridos foi realizado em outubro de 
1999 e as colheitas das amostras foram iniciadas em fevereiro de 2000, prolongando-se até o final de março de 2000.

$\mathrm{O}$ estabelecimento da cultura foi realizado em uma área plana de solo Latossólico vermelho amarelo. A análise do solo revelou as seguintes características: $\mathrm{pH}$ 5,1; $\mathrm{P}-96 \mathrm{mg} / \mathrm{dm}^{3} ; \mathrm{Al}^{+++}-1 \mathrm{mg} / \mathrm{dm}^{3} ; \mathrm{K}-3,4$ $\mathrm{cmol} / \mathrm{dm}^{3} ; \mathrm{Ca}^{++}-33 \mathrm{cmol} / \mathrm{dm}^{3} ; \mathrm{H}^{+}+\mathrm{Al}^{+++}-58 \mathrm{mg} /$ $\mathrm{dm}^{3} ; \mathrm{Mg}-17 \mathrm{cmol} / \mathrm{dm}^{3}$ e matéria orgânica- $46 \mathrm{mg} /$ $\mathrm{dm}^{3}$.

Para o estabelecimento da cultura de milho, a área foi arada e posteriormente gradeada para destorroamento, nivelamento e abertura dos sulcos. Por ocasião da semeadura, em sulcos espaçados de $80 \mathrm{~cm}$, foi aplicado adubo correspondente a $150 \mathrm{Kg}$ / ha, da fórmula 15-30-0 (N-P-K) e adubação orgânica com esterco bovino 30.000 Litros/ha. Realizou-se também uma adubação em cobertura correspondente a $250 \mathrm{~kg} / \mathrm{ha}$, da fórmula 25-0-5 (N-P-K).

Foram avaliados cinco cultivares de milho híbrido Pioneer: superprecoce 32R21 (P32R21), precoce 30R07 (P30R07), precoce 3041 (P3041), precoce 30F33 (P30F33) e semiprecoce 30F80 (P30F80), em cinco estádios de maturação da planta: 30,34 , 38, 42 e $46 \%$ de MS. Por ocasião das cinco colheitas com a finalidade de se alcançar os cinco estádios de maturação, observou-se o dia pós plantio (DPP), que correspondeu ao dia em que as amostras de cada híbrido foram colhidas no campo.

O delineamento experimental utilizado foi de blocos ao acaso, com cinco tratamentos e quatro repetições.

A parcela experimental foi constituída de 11 linhas de sete metros de comprimento e com espaçamento de $80 \mathrm{~cm}$, totalizando oito metros de largura, portanto, a área de cada parcela utilizada correspondeu a $61,6 \mathrm{~m}^{2}$. Foi considerada uma área útil de $36 \mathrm{~m}^{2} \mathrm{em}$ cada parcela, sendo que duas linhas laterais e 1 metro das duas extremidades foram consideradas como bordaduras, portanto, as amostras foram obtidas das nove linhas restantes, fazendo-se uso de toda parcela experimental.

Em todos os estádios de maturação, foram colhidas três plantas/linha/parcela, na qual, a colheita foi precedida de sorteio (ao acaso), preocupando-se em não se retirar plantas seguidamente, para evitar possíveis espaços (clarões) entre plantas, que pudessem também conduzir para um efeito competitivo entre estas. Destas, uma planta seria para amostra de planta inteira, e as demais, para amostras de colmo + bainha, lâmina foliar e grão, totalizando 27 plantas amostradas/parcela (9 linhas da parcela x 3 plantas/ linha) para cada estádio de maturação. Depois de cortadas no campo, todas as plantas da mesma parcela eram agrupadas, identificadas e transportadas para um local apropriado.

A colheita das amostras dos híbridos de milho foi adotada tentando obedecer cinco estádios de maturação da planta: 30, 34, 38, 42 e 46\% de MS, totalizando 100 amostras da planta inteira (5 estádios de maturação, 5 híbridos, 4 repetições). As colheitas obedeceram a uma ordem cronológica (ciclo de pendoamento), devido às características de cada híbrido, sendo o corte feito a partir dos $45 \mathrm{~cm}$ do solo, com foice. Para determinar o momento da colheita a campo das plantas, foi feito o monitoramento da consistência do grão nas plantas da bordadura de cada repetição, assim como, a utilização de dados referentes à MS dos mesmos híbridos, plantados no mesmo período, mas em ano anterior.

Para cada estádio de maturação, procedeu-se à pesagem (balança com capacidade de $15 \mathrm{~kg}$ ) da massa verde de cada planta colhida, individualmente e, posteriormente, foi feita a separação de colmo + bainha, lâmina foliar, grão, sabugo e palha para pesagem destes.

Após a pesagem, todo o material colhido foi triturado em tamanho de aproximadamente $2 \mathrm{~cm}$ por meio de picadeira de forragens, com exceção do grão. Após a homogeneização da forragem picada, foram retiradas amostras em torno de $500 \mathrm{~g}$, pesadas em balança com capacidade de $3 \mathrm{~kg}$ e foram présecas em saco de papel, em estufa a $55^{\circ} \mathrm{C}$ com ventilação forçada, até à obtenção de peso constante, para determinação da matéria seca. Para a amostragem dos grãos, retirou-se após homogeneização, amostras de $500 \mathrm{~g}$, seguindo-se o mesmo procedimento adotado para fração verde.

Determinou-se a percentagem de matéria seca (MS\%) a $105^{\circ} \mathrm{C}$ em estufa sem ventilação, das frações: planta inteira e colmo + bainha, segundo Silva (1998).

Da fração de colmo + bainha, amostras provenientes da homogeneização das dezoito plantas por parcela, determinou-se a digestibilidade in vitro da fibra em detergente neutro (DIVFDN) e a digestibilidade in vitro da MS (DIVMS), segundo Tilley \& Terry (1963), citados por Silva (1998).

$\mathrm{Na}$ planta inteira, amostras provenientes da homogeneização de nove plantas por parcela, foram determinadas a digestibilidade in vitro da matéria orgânica (DIVMO) e a digestibilidade in vitro da matéria seca (DIVMS), segundo Tilley \& Terry (1963), citados por Silva (1998). 
Antes do início das análises estatísticas, todas as variáveis foram testadas quanto à sua normalidade $\mathrm{e}$ homogeneidade da variância. As análises exploratórias dos dados mostraram que as variáveis não apresentaram distribuição normal $(\mathrm{P}<0,01)$. Então, admitiu-se uma distribuição gama para o erro em um Modelo Linear Generalizado (GLIM 4.0) como descrito por Nelder \& Wedderburn (1972).

\section{Resultados e Discussão}

Os teores de matéria seca (MS) estimados dos cinco híbridos, nos diferentes estádios de maturação, estão apresentados na Tabela 1. Verificou-se efeito cúbico $(\mathrm{P}<0,05)$ dos híbridos de milho e dias pós plantio (DPP), para os teores de MS. Este comportamento, segundo Lopes \& Maestri (1981), é explicável devido às transformações governadas tanto pelas condições internas de crescimento da planta (composição morfológica e translocação de nutrientes), como pelas externas (temperatura e umidade).

A digestibilidade in vitro da matéria seca (DIVMS) da fração colmo + bainha apresentou efeito cúbico $(\mathrm{P}<0,01)$ para os híbridos de milho e dias pós plantio (DPP) e as equações de regressão estão mostradas na Tabela 2.

A menor DIVMS do colmo + bainha a partir das equações de regressão, foi observada para o híbrido superprecoce P32R21, que variou de 20,72 a 29,46\%, quando os teores de MS na planta inteira, elevaramse de 30 a $35 \%$, considerando como o intervalo ideal de matéria seca, para planta de milho ser colhida, para o processo de ensilagem. Se considerarmos, para o híbrido superprecoce P32R21, uma maior faixa de variação de MS, isto é, para os valores extremos de MS obtidos quando da colheita do híbrido, de $25,85 \%$ de MS (125 DPP) a 39,75\% de MS (144 DPP), verificou-se aumento na DIVMS de 24,09 para 38,49\%, começando a decair logo após.

O comportamento cúbico verificado para os coeficientes de digestibilidade é decorrente, provavelmente, do mesmo comportamento também observado para a percentagem de nutrientes (proteína bruta, fibra em detergente neutro, fibra em detergente ácido, nitrogênio insolúvel em detergente neutro e lignina) avaliados no colmo + bainha em função de dias pós plantio. O comportamento cúbico pode ser explicado pela concentração e diluição dos nutrientes, que podem variar com o avanço do estádio vegetativo e também devido ao processo de translocação dos nutrientes entre as estruturas da planta.

A DIVMS do colmo + bainha não variou na faixa de 30 a $35 \%$ de MS na planta, para os híbridos precoces P30R07 (32,87 a 32,62\%), P3041 (26,74 a $24,27 \%$ ) e P30F33 (33,79 a 33,96\%). Considerando uma maior amplitude para o teor de MS, ainda verificase pouca variação para a DIVMS do colmo + bainha para esses híbridos. O híbrido precoce P30R07 atingiu o maior valor de DIVMS de $35,51 \%$ com $46,70 \%$ de MS (aos 148 DPP). Para o híbrido P3041, o maior valor de DIVMS foi de $29,75 \%$, com $24,69 \%$ de MS (131 DPP) e a partir daí, a DIVMS diminui até o valor de $24,00 \%$ com 35,76\% de MS (146 DPP), para aumentar em 3 unidades percentuais com $40,46 \%$ de

Tabela 1 - Valores estimados dos teores de matéria seca (MS) na matéria natural dos híbridos de milho, em função dos dias pós plantio (DPP), em cinco estádios de maturação

Table 1 - Estimated values of dry matter, fresh forage as a function of age (days after seeding - DAS) at five maturity stages Híbridos de milho

Corn hybrid

\begin{tabular}{|c|c|c|c|c|c|c|c|c|c|}
\hline \multicolumn{2}{|c|}{ P32R $21^{1}$} & \multicolumn{2}{|c|}{ P30R072 } & \multicolumn{2}{|c|}{ P3041 ${ }^{3}$} & \multicolumn{2}{|c|}{ P30F334 } & \multicolumn{2}{|c|}{$\mathrm{P} 30 \mathrm{~F} 80^{5}$} \\
\hline DPP & $\% \mathrm{MS}$ & DPP & $\% \mathrm{MS}$ & DPP & $\% \mathrm{MS}$ & DPP & $\% \mathrm{MS}$ & DPP & $\% \mathrm{MS}$ \\
\hline$D A S$ & $\% D M$ & $D A S$ & $\% D M$ & $D A S$ & $\% D M$ & $D A S$ & $\% D M$ & $D A S$ & $\% D M$ \\
\hline 125 & 25,85 & 128 & 33,13 & 127 & 26,11 & 129 & 29,17 & 135 & 20,74 \\
\hline 129 & 27,69 & 134 & 33,76 & 134 & 25,42 & 135 & 31,71 & 142 & 25,85 \\
\hline 135 & 32,62 & 141 & 39,90 & 141 & 30,80 & 142 & 35,35 & 151 & 28,37 \\
\hline 142 & 38,93 & 149 & 47,40 & 149 & 38,28 & 151 & 40,05 & 157 & 30,68 \\
\hline 151 & 39,27 & 156 & 48,27 & 156 & 40,46 & 157 & 42,54 & 164 & 37,26 \\
\hline
\end{tabular}

$1 \% \mathrm{MS}=7434-1789-126,1^{*} \mathrm{DPP}+0,9373^{*} \mathrm{DPP}^{2}-0,002305^{*} \mathrm{DPP}^{3}$

$2 \% \mathrm{MS}=7434-158,5^{*} \mathrm{DPP}+1,125^{*} \mathrm{DPP}^{2}-0,002644^{*} \mathrm{DPP}{ }^{3}$

$3 \% \mathrm{MS}=7434-684,4-143,1 \mathrm{DPP}+1,009^{*} \mathrm{DPP}^{2}-0,002355^{*} \mathrm{DPP}^{3}$

$4 \% \mathrm{MS}=7434-6502-19,91 \mathrm{DPP}+0,1432^{*} \mathrm{DPP}^{2}-0,0003342^{*} \mathrm{DPP}^{3}$

$5 \% \mathrm{MS}=7434-12711+106,7^{\star} \mathrm{DPP}-0,7169^{*} \mathrm{DPP}^{2}+0,001609^{*} \mathrm{DPP}^{3}$ 
Tabela 2 - Porcentagens médias e equações de regressão dos teores de digestibilidade in vitro da matéria seca (DIVMS) e digestibilidade in vitro da fibra em detergente neutro (DIVFDN) do colmo + bainha dos híbridos de milho, nos diferentes estádios de maturação

Table 2 - Percentage mean and regression equation at dry matter in vitro digestibility (IVDMD) and neutral detergent fiber in digestibility (IVDNDF) stem + sheath the corn hybrid at different maturity stages

\begin{tabular}{lcc}
\hline $\begin{array}{l}\text { Híbrido } \\
\text { Hybrid }\end{array}$ & $\begin{array}{c}\text { Médias } \\
\text { Means }\end{array}$ & \multicolumn{1}{c}{$\begin{array}{c}\text { Equação de regressão } \\
\text { Regression equation }\end{array}$} \\
\hline P32R21 & $25,56 \pm 6,37$ & DIVMS $=29753-656,8 * \mathrm{DPP}+4,823 * \mathrm{DPP}^{2}-0,01177^{*} \mathrm{DPP}^{3}$ \\
P30R07 & $33,37 \pm 1,27$ & DIVMS $=29753-25719-86,35 * \mathrm{DPP}+0,6192 * \mathrm{DPP}^{2}-0,001475^{*} \mathrm{DPP}^{3}$ \\
P3041 & $26,65 \pm 2,36$ & DIVMS $=29753-35847+131,9 * \mathrm{DPP}-0,9436 * \mathrm{DPP}^{2}+0,002241 * \mathrm{DPP}^{3}$ \\
P30F33 & $32,71 \pm 1,64$ & DIVMS $=29753-35355+118,2 * \mathrm{DPP}-0,8237 * \mathrm{DPP}^{2}+0,001907 * \mathrm{DPP}^{3}$ \\
P30F80 & $34,53 \pm 6,25$ & DIVMS $=29753-31637+30,88 * \mathrm{DPP}-0,1526 * \mathrm{DPP}^{2}+0,0002151 * \mathrm{DPP}^{3}$ \\
P32R21 & $24,29 \pm 5,82$ & DIVFDN $=28030-611 * \mathrm{DPP}+4,435 * \mathrm{DPP}^{2}-0,01067 * \mathrm{DPP}^{3}$ \\
P30R07 & $22,67 \pm 0,66$ & DIVFDN $=28030-29174+23,82 * \mathrm{DPP}-0,1615 * \mathrm{DPP}^{2}+0,000363 * \mathrm{DPP}^{3}$ \\
P3041 & $26,20 \pm 2,85$ & DIVFDN $=22030-29959+45,78 * \mathrm{DPP}-0,3528 * \mathrm{DPP}^{2}+0,000895 * \mathrm{DPP}^{3}$ \\
P30F33 & $21,16 \pm 0,79$ & DIVFDN $=28030-30207+45,41 * \mathrm{DPP}-0,3119 * \mathrm{DPP}^{2}+0,000712 * \mathrm{DPP}^{3}$ \\
P30F80 & $20,26 \pm 2,93$ & DIVFDN $=28030-15193-257,7 * \mathrm{DPP}+1,723 * \mathrm{DPP}^{2}-0,003831 * \mathrm{DPP}^{3}$ \\
\hline
\end{tabular}

DPP: dias pós plantio (dias).

DAS: days after seeding (days).

MS (156 DPP). O híbrido P30F33 atingiu maior valor de DIVMS (35,02\%) do colmo, com 35,57\% de MS (136 DPP), diminuindo em 4 unidades percentuais com 42,55\% de MS, aos 157 DPP (Tabela 2).

Para o híbrido semiprecoce $\mathrm{P} 30 \mathrm{~F} 80$ o maior valor observado para a DIVMS do colmo + bainha foi de $41,00 \%$, com 27,7\% de MS (148 DPP), reduzindo para $37,19 \%$, com $30,0 \%$ de MS (155 DPP), e para $28,22 \%$, com $35,0 \%$ de MS (162 DPP), continuando a declinar.

Verifica-se que, entre os híbridos estudados, considerando-se a elevação nos teores de MS da planta de 25 para $40 \%$, as maiores variações nos coeficientes de digestibilidade da MS do colmo + bainha foram para o híbrido mais tardio (semiprecoce P30F80), com mudanças em torno de 15 unidades percentuais na digestibilidade (diminui) e para o híbrido superprecoce P32R21, com variação em torno de 14 unidades percentuais (aumentou). Todavia para os demais híbridos, esta variação ficou em torno de 4 unidades percentuais. A maior variabilidade na DIVMS do colmo + bainha nos diferentes estádios de maturação, para os híbridos superprecoce P32R21 e o semiprecoce $\mathrm{P} 30 \mathrm{~F} 80$ em relação aos demais híbridos, é observada pelas médias e os desvios padrão da média. Estes valores foram de 25,56 $\pm 6,37 \%, 33,37$ $\pm 1,27 \%, 26,65 \pm 2,36 \%, 32,71 \pm 1,64 \%$ e $34,53 \pm$ 6,25\%, respectivamente, para os híbridos P32R21, P30R07, P3041, P30F33 e P30F80.

Os resultados observados para os híbridos de milho, com exceção do semiprecoce P30F80 em que se observou redução na digestibilidade do colmo com o avanço do estádio vegetativo, os demais variaram pouco e o superprecoce aumentou, contrariando em parte as observações de Buxton et al. (1996), Jobim et al. (1997) e Nussio et al. (2001). Estes autores relataram que a elevação nos teores de MS desde o estádio de grãos leitosos (25\% MS) até o de grãos duros $(40 \%$ MS) resultaram em redução na digestibilidade do colmo, devido ao processo de translocação dos carboidratos solúveis do colmo para produção de grão, pois o teor de carboidratos solúveis no colmo é inversamente proporcional ao conteúdo de grãos.

Se fosse considerada apenas a faixa de 30 a $35 \%$ de MS na planta inteira, recomendada como o intervalo ideal para o processo de ensilagem, para o superprecoce P32R21 haveria aumento na DIVMS e para o semiprecoce P30F80, redução na DIVMS do colmo + bainha, para ambos em torno de 9 unidades percentuais. A redução observada na digestibilidade da MS do colmo + bainha para o híbrido semiprecoce pode ser em parte explicada, pelo aumento no teor de lignina de 10,07 a 13,15\%. Para o híbrido superprecoce P32R21 observou-se menor variação e menor teor de lignina do colmo + bainha $(9,61$ a $10,66 \%)$ entre os híbridos avaliados. Penati (1995) avaliando vinte cultivares de milho observou que dentre os componentes da parede celular que mais influenciam na qualidade da MS da planta de milho é a percentagem de lignina, cujos teores observado para haste variaram de 6 a 12\%. Semelhante ao observado no presente trabalho, o referido autor encontrou correlação baixa e negativa para os teores de lignina com a DIVMS do 
colmo, porém sugeriu que os estudos devem enfatizar a composição físico-química e a disposição tridimensional da lignina, ligada aos demais componentes da parede celular. Estes fatores podem explicar melhor a qualidade do colmo ou da planta de milho do que o próprio teor de lignina. Penati (1995) encontrou grande amplitude na digestibilidade do colmo, variando de 40,1 a $59,7 \%$.

A lignina na parede primária não tem efeito sobre a digestão da celulose, pois esta está acessível aos microrganismos ruminais, mas, à medida, em que a planta envelhece, a lignificação ocorre na parede secundária (quando o crescimento termina), tornandose mais espessa e, deste modo, constitui uma barreira para a digestão da celulose (Inra, 1998).

Ao avaliar o comportamento dos nutrientes presentes no colmo + bainha nos diferentes estádios de maturação (25 a 40\% de MS), verificou-se que os teores de PB praticamente não variaram de 3,58 a $3,86 \%$, sendo que 40 a $60 \%$ desta fração, encontrouse indisponível como mostrou os valores obtidos para o nitrogênio insolúvel em detergente neutro (NIDA) em relação ao $\mathrm{N}$ total. Ainda, os teores da FDN e da FDA no colmo + bainha variaram pouco, para os diferentes estádios de maturação, em média menos de três unidades percentuais para a FDN e de três a seis unidades percentuais para a FDA. A exceção foi para o híbrido semiprecoce $\mathrm{P} 30 \mathrm{~F} 80$ cujos teores de FDN variaram em torno de quatro unidades percentuais e os teores da FDA variaram, em torno de onze unidades percentuais, porém decrescente com o avanço do estádio de maturação.

Estudos de correlações foram feitos entre a DIVMS e os teores de PB, NIDA, FDN, FDA e lignina do colmo + bainha. Os coeficientes de correlação foram baixos para estas variáveis, sendo o mais pronunciado, porém, também baixo e positivo, para os teores de FDA e DIVMS do colmo + bainha $\left(\mathrm{R}^{2}=28,0 \%\right)$.

Os coeficientes de digestibilidade in vitro da fibra em detergente neutro (DIVFDN) do colmo + bainha, dos híbridos de milho superprecoce P32R21, precoces P30R07, P30F33, P3041 e semiprecoce P30F80, para os cinco estádios de maturação, apresentaram valores médios e desvio padrão, respectivamente, de: $24,29 \pm 5,82 \%, 22,67 \pm 0,66 \%, 26,20 \pm 2,85 \%, 21,16$ $\pm 0,79 \%$ e $20,26 \pm 2,93 \%$. Os híbridos diferiram entre si $(\mathrm{P}<0,05)$, e observou-se efeito cúbico $(\mathrm{P}<0,01)$ da DIVFDN para os diferentes híbridos, em função de dias pós plantio (Tabela 2).

Semelhante aos resultados da DIVMS, para o híbrido superprecoce P32R21, verificou-se uma evolução na DIVFDN do colmo + bainha, de 16,94 para 23,94\% que acompanhou a elevação nos teores de MS na planta inteira de 30 a $35 \%$ e para o semiprecoce a DIVFDN decresceu de $22,41 \%$ para $20,41 \%$. Constatou-se, com exceção do superprecoce P32R21, que a DIVFDN do colmo + bainha dos demais híbridos praticamente não variaram, como pode ser verificado pelo desvio-padrão em torno da média.

Entre as variáveis avaliadas, os estudos de correlação mostraram que os teores de FDN podem ter correspondência com a DIVFDN do colmo + bainha nos diferentes estádios de maturação, porém, essa correlação não explicou mais que $48,6 \%$ da variação $\left(R^{2}=48,6 \%\right)$. Os coeficientes de correlação $\left(\mathrm{R}^{2}\right)$ para a DIVFDN do colmo + bainha e a DIVMS e com os teores de FDA e de lignina, foram inferiores, respectivamente de 36,$4 ; 25,5$ e $21,9 \%$.

Um diferencial entre a DIVMS e a DIVFDN do colmo + bainha foi verificado para os híbridos precoces P30R07 e o P30F33 de 11 unidades percentuais, para o semiprecoce P30F80 de 14 unidades percentuais e somente em torno de uma unidade percentual para os superprecoce P32R21 e o precoce P3041. O diferencial na digestibilidade da MS e da parede celular, representada pela FDN do colmo + bainha pode estar ligado as contribuições do demais nutrientes presentes no conteúdo celular (proteína, extrato etéreo, carboidratos solúveis e amido). Provavelmente além da contribuição da PB, cujos teores no colmo + bainha variam pouco (de 3,31 a 4,07\%), independentemente do híbrido e estádio de maturação, os outros componentes podem estar determinando este diferencial.

A digestibilidade in vitro da matéria seca (DIVMS) da planta inteira, para os híbridos de milho nos diferentes estádios de maturação, diferiu $(\mathrm{P}<0,01)$ entre híbridos e observou-se efeito cúbico para a DIVMS dos híbridos de milho e DPP (Tabela 3).

A elevação no teor de MS de 30 a $35 \%$ nas planta inteira, que corresponde com a consistência dos grãos variando entre os estádios pastoso e o farináceo duro (Nussio et al., 2001), teve efeito pronunciado na DIVMS da planta inteira dos híbridos precoce $\mathrm{P} 30 \mathrm{~F} 33$ e do superprecoce P32R21. O aumento foi de quinze unidades percentuais para a DIVMS para o híbrido precoce P30F33, de 52,93\% (29,93\% MS e 131 DPP) para $67,54 \%(34,81 \%$ MS e141 DPP) e para o híbrido superprecoce P32R21 o aumento foi de cinco unidades percentuais de $61,33 \%(29,88 \%$ de MS e 132 DPP) para $66,52 \%$ (34,81\% de MS e 137 DPP). 
Tabela 3 - Equação de regressão e porcentagens média (\%) dos teores de digestibilidade in vitro da matéria seca (DIVMS) e digestibilidade in vitro da matéria orgânica (DIVMO) da planta inteira dos híbridos de milho, nos diferentes estádios de maturação

Table 3 - Regression equation and percentage mean at dry matter in vitro digestibility (IVDMD) and organic matter in vitro digestibility (IVDMO) whole-plant the corn hybrid at different maturity stages

\begin{tabular}{lcc}
\hline $\begin{array}{l}\text { Híbrido } \\
\text { Hybrid }\end{array}$ & $\begin{array}{c}\text { Médias } \\
\text { Means }\end{array}$ & \multicolumn{1}{c}{$\begin{array}{c}\text { Equação de regressão } \\
\text { Regression equation }\end{array}$} \\
\hline P32R21 & $64,84 \pm 4,66$ & DIVMS $=3811+18798-495,9 * \mathrm{DPP}+3,627 * \mathrm{DPP}^{2}-0,00882 * \mathrm{DPP}^{3}$ \\
P30R07 & $63,52 \pm 2,13$ & DIVMS $=3811-80,4 * \mathrm{DPP}+0,5745 * \mathrm{DPP}^{2}-0,001367 * \mathrm{DPP}^{3}$ \\
P3041 & $60,14 \pm 4,65$ & DIVMS $=3811-6077+42,75 * \mathrm{DPP}-0,2551 * \mathrm{DPP}^{2}+0,0004904 * \mathrm{DPP}^{3}$ \\
P30F33 & $57,29 \pm 8,90$ & DIVMS $=3811-19511+319 * \mathrm{DPP}-2,144 * \mathrm{DPP}^{2}+0,004785 * \mathrm{DPP}^{3}$ \\
P30F80 & $62,82 \pm 2,86$ & DIVMS $=3811-171,8-67,76 * \mathrm{DPP}+0,4249 * \mathrm{DPP}^{2}-0,0008817 * \mathrm{DPP}^{3}$ \\
P32R21 & $72,34 \pm 2,94$ & $\mathrm{DIVMO}=15047-328,4 * \mathrm{DPP}+2,394 * \mathrm{DPP}^{2}-0,005801 * \mathrm{DPP}^{3}$ \\
P30R07 & $75,99 \pm 0,60$ & $\mathrm{DIVMO}=15047-12643-49,44 * \mathrm{DPP}+0,3492 * \mathrm{DPP}^{2}-0,0008203 * \mathrm{DPP}^{3}$ \\
P3041 & $63,87 \pm 1,74$ & $\mathrm{DIVMO}=15047-6142-188 * \mathrm{DPP}+1,327 * \mathrm{DPP}^{2}-0,003110 * \mathrm{DPP}^{3}$ \\
P30F33 & $72,85 \pm 4,93$ & DIVMO= $15047-17845+52,56 * \mathrm{DPP}-0,3132 * \mathrm{DPP}^{2}+0,0006036 * \mathrm{DPP}^{3}$ \\
P30F80 & $71,92 \pm 3,42$ & DIVMO $=15047-10619-82,75 * \mathrm{DPP}+0,5202 * \mathrm{DPP}^{2}-0,001082 * \mathrm{DPP}^{3}$ \\
\hline
\end{tabular}

DPP: dias pós plantio (dias).

DAS: days after seeding (days).

Os resultados obtidos para o os híbridos superprecoce P32R21 e o precoce P30F33 contrastam em parte com aqueles observados por Demarquilly (1994), Lavezzo et al. (1997) e Mayombo et al. (1997) que encontraram pouca variação na digestibilidade da MS e MO com o avanço da maturação do milho. Entretanto, para os demais híbridos também pouca variação foi observada para a D IVMS da planta inteira. Para o híbrido precoce P30R07, com o teor de matéria seca entre 33,13 e $34,39 \%$ de MS, a digestibilidade variou de 65,60\% (128 DPP) a 63,92\% (135 DPP). O híbrido precoce $\mathrm{P} 3041$ não variou, com $29,88 \%$ de MS (140 DPP) a DIVMS foi de $64,69 \%$ e com $34,81 \%$ de MS (145 DPP) foi de 64,31\%. Para o híbrido semiprecoce P30F80, a variação foi em torno de três unidades percentuais, de 61,28\% (29,69\% MS e 155 DPP) para $64,58 \%$ (34,78\% MS e $162 \mathrm{DPP})$.

Segundo Buxton et al. (1996), ao contrário das outras espécies, o milho praticamente não tem a sua digestibilidade reduzida pela maturação. O enchimento do grão e a perda de digestibilidade dos componentes da haste são eventos concomitantes, refletindo em mínima variação na digestibilidade da MS da planta inteira, com o aumento no teor de MS (Nussio, 1991, Nussio et al., 2001). Todavia, no presente trabalho, com exceção para o híbrido mais tardio, o semiprecoce P30F80, em que se observou redução na DIVMS e na DIVFDN do colmo + bainha, para os demais híbridos não foram observadas reduções na digestibilidade do colmo, à medida que se elevou o teor de MS, como já discutido anteriormente.

A maior média de DIVMS da planta inteira foi observada para o híbrido superprecoce P32R21 (64,84 $\pm 4,66 \%)$ e a menor para o precoce P30F33 $(57,29 \pm$ $8,90 \%$ ), para os diferentes estádios de maturação.

O diferencial entre a DIVMS do colmo + bainha e a DIVMS da planta inteira variou de 24,58 a 39,28 unidades percentuais, valores bastante superiores aos apresentados por Nussio et al. (2001). Este diferencial foi menor para o precoce $\mathrm{P} 30 \mathrm{~F} 33$ e maior para o híbrido superprecoce P32R21 e estaria relacionado às contribuições dos demais componentes não estruturais da planta inteira. Os dados mostraram que há uma correlação negativa entre a digestibilidade in vitro da matéria orgânica (DIVMO) e a percentagem de colmo + bainha na planta inteira $\left(\mathrm{R}^{2}=-43,67 \%\right)$ e uma correlação positiva com a percentagem de espiga na planta inteira $\left(R^{2}=39,95 \%\right)$, porção mais digestível. O híbrido superprecoce P32R21 apresentou a maior percentagem de grão e de espiga e as menores percentagens de lâmina foliar e de colmo + bainha na planta inteira, para os diferentes estádios de maturação. A percentagem de colmo + bainha na MS da planta inteira apresentou correlação significativa e negativa $\left(\mathrm{R}^{2}=-79,0 \%\right)$ com o avanço do estádio de maturação (teores de MS) para os híbridos avaliados e a percentagem de espiga na MS da planta inteira correlacionou-se negativamente com a percentagem de colmo + bainha $\left(R^{2}=-93,0 \%\right)$ e com a percentagem de lâmina foliar $\left(R^{2}=-90,0 \%\right)$.

Os coeficientes de correlação, para a DIVMS da planta inteira e as variáveis avaliadas, foram baixos. Os coeficientes de correlação $\left(\mathrm{R}^{2}\right)$ para a DIVMS e a percentagem de colmo + bainha foi de $-29,6 \%$, para 
a percentagem de espiga foi de $14,11 \%$, para a percentagem de grão foi de $11,5 \%$ e para a percentagem de amido no grão de $-31,27 \%$. Do mesmo modo, ausência de correlação entre o teor de amido e a digestibilidade da MO foi verificado por Andrieu et al. (1993). Ainda, foram verificados baixos coeficientes de correlação para a DIVMS da planta inteira, com os teores de PB no grão $\left(\mathrm{R}^{2}=17,2 \%\right)$, com a percentagem de lignina no colmo + bainha $\left(\mathrm{R}^{2}\right.$ $=24,5 \%)$, com os teores de NIDA na folha $\left(\mathrm{R}^{2}=-\right.$ $24,3 \%)$, com os teores de $\mathrm{PB}$ na folha $\left(\mathrm{R}^{2}=-11,0 \%\right)$ e com os teores de PB no colmo $\left(R^{2}=-17,3 \%\right)$. Os baixos coeficientes de correlação podem ser devido às pequenas variações observadas para os teores de nutrientes e para os coeficientes da DIVMS da planta inteira, à medida que avança o estádio vegetativo, após a formação do grão.

Os coeficientes da DIVMS da planta inteira são superiores a alguns valores relatados na literatura (Seiffert et al., 1978, Valente et al., 1984b, Bezerra et al., 1993, Hunt et al., 1993, Pereira et al., 1993, Quadros et al., 1994, Almeida Filho 1996, Almeida Filho et al., 1999), inferiores a outros ( Johnson \& Mcclure 1968, Purger et al., 1980, Allen, 1990, Mayombo et al., 1997) e praticamente iguais aos valores de Obeid et al. (1985).

Para a DIVMO da planta inteira, observou-se diferença $(\mathrm{P}<0,01)$ entre os híbridos, e efeito cúbico $(\mathrm{P}<0,01)$ em relação aos dias pós plantio (Tabela 3 ), semelhante ao comportamento verificado para a DIVMS. As médias e os desvios padrão para os híbridos superprecoce P32R21, para os precoces P30R07, P3041, P30F33 e o semiprecoce P30F80 foram, respectivamente, de 72,34 $\pm 2,94 \%, 75,99 \pm$ $0,60 \%, 63,87 \pm 1,74 \%, 72,85 \pm 4,93 \%$ e $71,92 \pm 3,42 \%$ (Tabela 3). Estes valores médios foramsemelhantes à variação de $71,50 \pm 2,2 \%$ e de 65,20 a 73,50\% descrita por Demarquilly, (1994) e Inra Lusignan (1998), superiores aos dados encontrados por Gomide et al. (1987), Oliveira et al. (1987), Pereira et al. (1993), Silva et al. (1994), Quadros et al. (1994), Barrière et al. (1997) e Flaresso et al. (2000) e inferiores à DIVMO de $77,50 \%$ encontrada por Mayombo et al. (1997).

Com o aumento nos teores de 30 para $35 \%$ de MS, semelhante a DIVMS, elevou-se a DIVMO da planta inteira do híbrido precoce P30F33, de 69,48\% para $78,25 \%$. Aumentos em torno de 4 unidades percentuais também foram verificados para os híbridos superprecoce P32R21 e o semiprecoce P30F80 e os demais híbridos não variaram.
Os coeficientes de correlações também foram baixos para DIVMO da planta inteira e os teores de MS, de FDA, de lignina e de FDN. Estes foram de $34,0 \%, 22,5 \%, 14,0 \%, 11,0 \%$, respectivamente.

As produções média de matéria seca em tonelada /hectare (para os cinco estádios de maturação) para os híbridos superprecoce P32R21, para os precoces P30R07, P3041, P30F33 e para o semiprecoce P30F80, foram de $15,65,16,37,15,14,17,24$ e 15,50 t/ha, respectivamente. Embora, o híbrido superprecoce P32R21 tenha apresentado a menor $(\mathrm{P}<0,05)$ produção $(15,65 \mathrm{t} /$ ha) em relação ao precoce $\mathrm{P} 30 \mathrm{~F} 33$ $(17,24 \mathrm{t} / \mathrm{ha})$, apresentou a maior produção de matéria seca digestível (10,15 t/ha v.s. 9,88 t/ha), levando em consideração a média observada para os coeficientes de DIVMS da planta inteira. As produções de MS digestível observadas para os híbridos precoce de P30R07, P3041 e o semiprecoce P30F80 foram, respectivamente, de 10,40; 9,10 e 9,73 t/ha.

\section{Conclusões}

A elevação nos teores de MS na planta de 25 a $40 \%$ refletiu em mudanças na digestibilidade da MS (DIVMS) do colmo + bainha, em torno de $60 \%$ para o híbrido superprecoce P30R21 (aumentou) e 36\% para o semiprecoce P30F80 (diminui) e para os híbridos precoces P30R07, P3041 e P30F33 não variou.

Com exceção do superprecoce P32R21, em que se verificaram aumentos na digestibilidade da fibra em detergente neutro (DIVFDN) do colmo + bainha, à medida que se elevaram os teores de MS de 30 para $35 \%$, para os demais híbridos praticamente não variaram.

A elevação nos teores de MS de 30 para $35 \%$ aumentou a DIVMS da planta inteira do híbrido precoce P30F33, em 15 unidades percentuais, e do superprecoce P32R21 e do semiprecoce P30F80 em torno cinco a quatro unidades percentuais, e para os precoces $\mathrm{P} 30 \mathrm{R} 07$ e o P3041 não variou. $\mathrm{O}$ mesmo comportamento foi verificado para a DIVMO da planta inteira.

O híbrido superprecoce apresentou, em média,o maior valor para a DIVMS, de 64,84 $\pm 4,66 \%$ e o menor valor foi para o precoce $\mathrm{P} 30 \mathrm{~F} 33$, de 57,29 $\pm 8,90 \%$.

\section{Agradecimento}

À Empresa Sementes Pioneer, pela oportunidade oferecida e pelo apoio para a realização deste trabalho.

À Fundação $\mathrm{ABC}$, pelo desenvolvimento do campo experimental. 


\section{Literatura Citada}

ALLEN, M. All corn silage is not created equal.Fort Atkinson: Hord's Dairyman, 1990. 766p.

ANDRIEU, J.; DEMARQUILLY, C.; DARDENNE, P. et al. Composition and nutritive value of whole maize plants fed fresh to sheep. 1. Factors of variation. Annimal Zootech, v.42, p.221-249, 1993.

ALMEIDA FILHO, S.L. Avaliação de cultivares de milho (Zea mays L.) para silagem Viçosa, MG: Universidade Federal de Viçosa, 1996. 52p. Dissertação (Mestrado em Zootecnia) - Universidade Federal de Viçosa, 1996.

ALMEIDA FILHO, S.F.; FONSECA, D.M.; GARCIA, R. et al. Características agronômicas de cultivares de milho (Zea mays L.) e qualidade dos componentes e da silagem. Revista Brasileira de Zootecnia, v.28, n.1, p.7-13, 1999.

BARRIÈRE, Y.; ARGILLIER, O.; MICHALET-DOREAU, B. et al. Relevant traits, genetic variation and breeding strategies en early silage maize. Agronomie, v.17, p.395-411, 1997.

BEZERRA, E.S.; Von TIESENHAUSEN, I.M.E.V.; OLIVEIRA, A.I.G. et al. Valor nutricional das silagens de milho, milho associado com sorgo e rebrotas de sorgo. Revista Brasileira de Zootecnia, v.22, n.6, p.1045-1054, 1993.

BUXTON, D.; REDFEARN, D.; JUNG, H. Improving forage quality. Improving forage quality - related characteristics of corn. In: INFORMATIONAL CONFERENCE WITH DAIRY AND FORAGE INDUSTRIES, 1996, Nantes, France. Proceedings... Nantes: 1996. p.23-28.

DEMARQUILLY, C. Facteurs de variation de la valeur nutritive du mais ensilage. Production Animal, v.7, n.3, p.177-189, 1994.

FLARESSO, J.A.; GROSS, C.D.; ALMEIDA, E.D. Cultivares de milho (Zea mays L. e Sorgo (Sorghum bicolor (L.) Moench.) para ensilagem no alto Vale do Itajaí, Santa Catarina.Revista Brasileira de Zootecnia, v.29, n.6, p.1608-1615, 2000.

GOMIDE, J.A.; ZAGO, C.P.; CRUZ, M.E. et al. Milho e sorgo em cultivos puros ou consorciados com soja, para produção de silagens. Revista Brasileira de Zootecnia, v.16, n.4, p.308-317, 1987.

HUNTER, R.B. Selection and evaluation procedures for whole plant corn silage. Canadian Journal Animal Science, v.58, n.7, p.661-678, 1978.

HUNT, C.W.; KEZAR, W.; HINMAN, D.D. et al. Effects of hybrid and ensiling and without a microbial inoculant on the nutritional characteristics of whole plant corn. Journal of Animal Science, v.71, n.1, p.38-43, 1993.

INSTITUT NATIONAL DE LA RECHERCHE AGRONOMIQUE - INRA. Rencontres chercheurs-éleveurs. Production Laitiere Magazine, v.277, n.2, p.42-50, 1998.

JOBIM, C.C.; REIS, R.A.; ROSA, B. Avaliação da silagem de grãos úmidos de milho (Zea mays L.).Pesquisa Agropecuária Brasileira, v.32, n.3, p.311-318, 1997.

JOHNSON, R.R.; McCLURE, K.E. Corn plant maturity IV. Effects on digestibility of corn silage in sheep. Journal of Animal Science, v.27, n.2, p.1102-1109, 1968.

JUNG, H.G. Forage lignins and their effects on fiber digestibility. Agronomie Journal, v,81, p.33-38,1989.

(Escrever o sobrenome do terceiro autor)LAVEZZO, W.; LAVEZZO, O.E.N.M.; NETO, O.C. Estádio de Desenvolvimento do milho. Efeito sobre produção, composição da planta e qualidade da silagem. Revista Brasileira de Zootecnia v.26, n.4, p.675-682, 1997a.

MAYOMBO, A.P.; DUFRASNE, I.; HORNICK, J.L. et al. Influencie du stade de maturité de la plante de may recolteé pour ensilage sur la composition, la digestibilité aparente, les caractéristiques de fermentation dans le rume et les performances zootechniques chez le taurillon à I'engraissement. Animal Zootech, v.46, p.43-55, 1997.

NELDER, J.A.; WEDDERBURN, R.W.M. Generalized linear models. Journal of the Royal Statistical Society, v.A135, p.370-384, 1972.

NUSSIO, L. G. Cultura de milho para produção de silagem de alto valor alimentício. In: SIMPÓSIO SOBRE NUTRIÇÃO DE BOVINOS, 4., 1991, Piracicaba. Anais... Piracicaba: Escola Superior de Agricultura "Luiz de Queiroz, 1991. 302p.

NUSSIO, L.G.; CAMPOS, F.P.; DIAS, F.N. Importância da qualidade da porção vegetativa no valor alimentício da silagem de milho. In: SIMPÓSIO SOBRE PRODUÇÃO E UTILIZAÇÃO DE FORRAGENS CONSERVADAS, 1., 2001, Maringá. Anais... Maringá: Universidade Estadual de Maringá, 2001. p.127-145.

OBEID, J.A.; ZAGO, C.P.; GOMIDE, J.A. Qualidade e valor nutritivo de silagem consorciada de milho (Zea mays $L$.) com soja anual (Glycine Max. Merrill). Revista Brasileira de Zootecnia, v.14, n.4, p.439-446, 1985.

OLIVEIRA, M.D.S.; SAMPAIO, A.A.M.; VIEIRA, P.F. et al. Efeito do olaquindox sobre o valor nutritivo da silagem de milho. Revista Brasileira de Zootecnia, v. 16, n.5, p.426-431, 1987.

PENATI, M.C. Relação de alguns parâmetros agronômicos e bromatológicos de híbridos de milho (Zea mays L.) com a produção, digestibilidade e teor de matéria seca na planta. Piracicaba: Escola Superior de Agricultura "Luiz de Queiroz", 1995.97p. Dissertação (Mestrado em Agronomia) - Escola Superior de Agricultura "Luiz de Queiroz", 1995.

PEREIRA, O.D.; OBEID, J.A.; GOMIDE, J.A. et al. Produtividade de uma variedade de milho (Zea mays $L$.) e de três variedades de sorgo (Sorghum bicolor L.) e o valor nutritivo de suas silagens. Revista Brasileira de Zootecnia, v.22, n.1, p.31-38, 1993.

PURGER, J.V.N.; LOPEZ, J. Avaliação químicae "in vivo"da silagem de milho (Zea mays L.) sem e com suplementação nitrogenada. Revista Brasileira de Zootecnia, v.9, n.3, p.360-372, 1980.

QUADROS, F.L.F.; GENRO, T.C.M.; ARAÚJO, J.B.E. et al. Qualidade da silagem de híbridos de milho (Zea mays $L$ ) e sorgo (Sorghum sp.). In: REUNIÃO ANUAL DA SOCIEDADE BRASILEIRA DE ZOOTECNIA, 31., 1994, Maringá. Anais... Viçosa, MG: Sociedade Brasileira de Zootecnia, 1994. p.357.

SEIFFERT, N.F.; PRATES, E.R. Forrageiras para ensilagem. II - Valor nutritivo e qualidade de silagem de cultivares de milho (Zea mays L.), sorgos (Sorghum sp.) e milhetos (Pennisetum americanum, Schum). Revista Brasileira de Zootecnia, v.7, n.2, p.183-195, 1978.

SILVA, A.W.L.; ALMEIDA, M.L.; MAFRA, A.L. et al. Avaliação de híbridos e variedades de milho para ensilagem. II Características químico-bromatológicas do material na colheita. In: REUNIÃO ANUAL DA SOCIEDADE BRASILEIRA DE ZOOTECNIA, 31., 1994, Maringá. Anais... Viçosa, MG: Sociedade Brasileira de Zootecnia, 1994. p.345.

SILVA, D.J. Análise de alimentos (Métodos químicose biológicos). Viçosa, MG: Universidade Federal de Viçosa, 1998. 166p.

VALENTE, J.O.; SILVA, J.F.C.; GOMIDE, J.A. Estudo de duas variedades de milho(Zea mays $L$ ), e de quatro variedades de sorgo para silagem. 2. Valor nutritivo e produtividade das silagens. Revista Brasileira de Zootecnia, v.13, n.1, p.74-81, 1984.

Recebido em: 28/02/02 Aceito em: 30/10/02 